\title{
A female patient with Xp21 gene deletion syndrome
}

\author{
Jungeun Kim ${ }^{\oplus}$, Hyunjoo Lee ${ }^{\circledast}$, Ji-Hoon $\mathrm{Na}{ }^{\circledR}$, and Young-Mock Lee*® \\ Department of Pediatrics, Gangnam Severance Children's Hospital, Yonsei University College of Medicine, Seoul, Korea
}

Xp21 contiguous gene deletion syndrome is associated with complex glycerol kinase deficiency, congenital adrenal hypoplasia, Duchene muscular dystrophy, and intellectual disability. Xp21 gene deletion syndrome is X-linked recessive, so most symptomatic patients are male, and only a few female symptomatic patients have been reported. We report the first female Korean case of an Xp21 deletion. NGS data were analyzed for copy number variation, and the Xp21 deletion (chr X: 29301056-31838200) was confirmed using real-time PCR.

Key words: Xp21 contiguous gene deletion syndrome, Duchenne muscular dystrophy, Creatine kinase.

\section{Introduction}

Xp21 contiguous gene deletion syndrome is associated with complex glycerol kinase deficiency, congenital adrenal hypoplasia, Duchenne muscular dystrophy (DMD), and intellectual disability [1]. The Xp21 chromosome includes the $G K, N R O B 1, D M D$, and IL TPAPL 1 genes. Among these, GK gene deletion leads to glycerol kinase deficiency, causing metabolic acidosis, recurrent hypoglycemia, and osteoporosis. NROB1 gene rearrangements cause congenital adrenal hypoplasia, which is associated with the fatal symptom experienced by patients with Xp21 gene deletion syndrome.

DMD gene deletion leads to DMD and Becker muscular dystrophy (BMD). The DMD phenotype is more severe than that of BMD, with earlier onset of symptoms. The absence of dystrophin protein causes neuromuscular symptoms and elevated serum creatine kinase (CK) levels. Patients with DMD are non-ambulatory at 9-10 years of age, while other symptoms start to appear around 12 years of age [2]. IL 1PAPL 1 gene deletion is associated with intellectual disability [1].

Xp21 gene deletion syndrome is $X$-linked recessive; therefore, most symptomatic patients are male, and only a few symptomatic female patients have been reported. We report the first case of a female Korean patient with Xp21 contiguous gene deletion.

\section{Case}

A 2-year-old female was referred to our hospital for evaluation of the genetic cause of a 4-fold increase in CK levels. She was born at 40 weeks of gestation without any perinatal events. She had one healthy older brother and did not have any family history of neuromuscular disorders. She had chickenpox at five months of age; laboratory findings at that time incidentally revealed elevated CK levels for the first time. Initial electrolyte analysis and acid-base balance were normal. Analysis of urine and plasma organic acid, including glyceric acid, was done, and there were no significant abnormalities. Newborn screening test, including $17-\alpha$-hydroxy progesterone and adrenocorti-

\footnotetext{
Received: 5 August 2021, Revised: 1 September 2021, Accepted: 3 September 2021, Published: 31 December 2021

*Corresponding author: Young-Mock Lee, M.D., Ph.D. (iD https://orcid.org/0000-0002-5838-249X

Department of Pediatrics, Gangnam Severance Hospital, Yonsei University College of Medicine, 211 Eonju-ro, Gangnam-gu, Seoul 06273, Korea.

Tel: +82-2-2019-3350, Fax: +82-2-2019-4881, E-mail: ymleemd@yuhs.ac

Conflict of interest: The authors declare that they do not have any conflicts of interest.

(a) This is an open-access article distributed under the terms of the Creative Commons Attribution Non-Commercial License (http://creativecommons.org/licenses/by-nc/4.0/) which permits unrestricted non-commercial use, distribution, and reproduction in any medium, provided the original work is properly cited.

(c) Copyright 2021 by the Korean Society of Medical Genetics and Genomics www.e-kjgm.org
} 
cotropic hormone/cortisol, was normal. Echocardiography and electrocardiography findings were normal, and cardiomegaly was not detected on chest radiography. Her height, weight, and

\section{$\mathrm{CK}(\mathrm{U} / \mathrm{L})$}

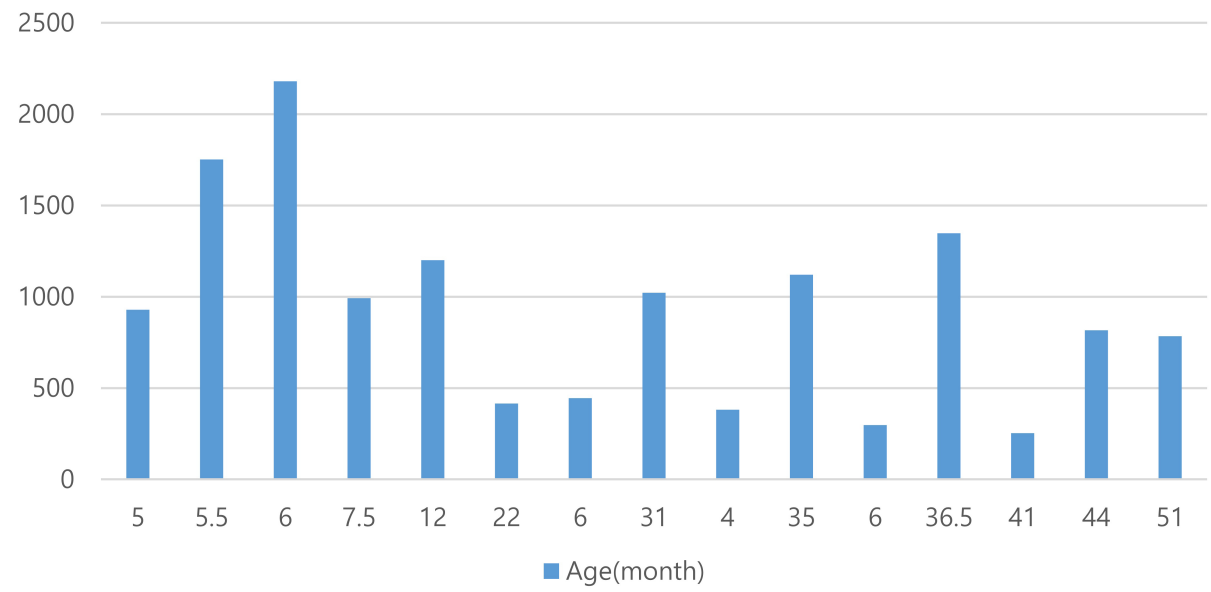

head circumference were in the 50th percentile, which is within the normal range for her age. She could control her neck at three months of age, sit without support at seven months, walk
Fig. 1. Creatin kinase level by age. CK creatin kinase. Normal range, 21-215 U/L.

(A)

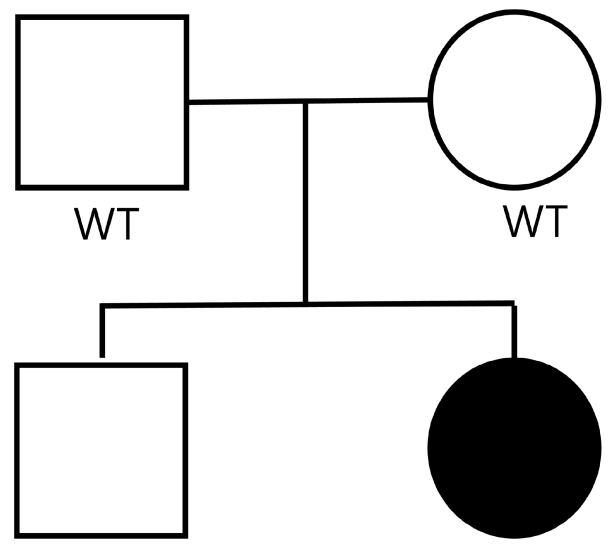

(B)

UCSC Genome Browser on Human Feb. 2009 (GRCh37/hg19) Assembly move $\ll<|\ll|<|>| \gg \mid \gg$ zoom in \begin{tabular}{|l|l|l|l|l|l|l|l|l|}
$1.5 x$ & $3 x$ & $10 x$ & base & zoom out & $1.5 x$ & $3 x$ & $10 x$ & $100 x$ \\
\hline
\end{tabular}

chrX:29,301,056-31,838,200 2,537,145 bp. enter position, gene symbol, HGVS or search terms go

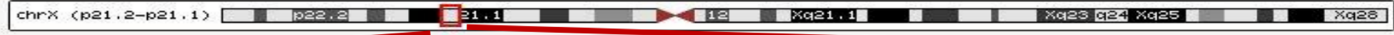

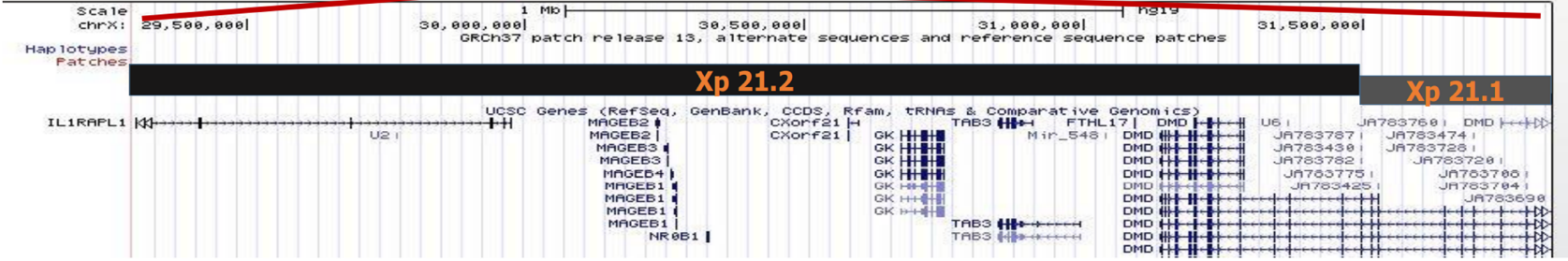

Fig. 2. (A) Pedigree of the patient with Xp21 gene deletion syndrome. (B) Gene copy number variation analysis of the patient with Xp21 gene deletion syndrome. 
at one year, and her other developmental milestones were attained normally. She had mild intellectual disability; therefore, she could not speak two-word phrases until the age of two. CK levels were assessed every 3 months and remained consistently elevated in the range of 600 to 1,300 (normal range: $30-135$ ) (Fig. 1). She was referred to the neurology department to evaluate the cause of CK elevation. We performed next-generation sequencing to identify the causative mutations for neuromuscular diseases, but no significant single nucleotide variant was detected. Xp21 deletion (chromosome X: 29301056-31838200) was identified and confirmed using real-time PCR. This deletion encompassed RefSeq genes, as found in the UCSC Genome Browser (http://genome.ucsc.edu/) (NCBIBuild37, hg19), comprising $D M D, G K, N R O B 1$, and IL IPAPL1. Trio analysis for proband and her asymptomatic parents was performed. Xp21 deletion was not detected in her parents, indicating that the deletion was de novo (Fig. 2). Real-time PCR confirmed that her parents have a normal copy of those genes on the X chromosome. Currently, at five years of age, her CK levels remain elevated, but she does not have any motor deficiencies.

\section{Discussion}

Xp21 gene deletion syndrome is associated with glycerol kinase deficiency, congenital adrenal hypoplasia, DMD, and intellectual disability. Clinical symptoms vary depending on the size of the deletion. Most female patients who are heterozygous for $X p 21$ deletion are asymptomatic owing to the remnant $X$ chromosome, whereas male patients with Xp21 gene deletion manifest with fatal symptoms such as electrolyte imbalance and hypotension. We report the case of the first symptomatic Korean female with Xp21 contiguous gene deletion syndrome. She had elevated CK levels and mental retardation.

Patients with glycerol kinase deficiency can be symptomatic with metabolic acidosis, vomiting, or lethargy [3]. Symptoms of glycerol kinase deficiency often occur between the ages of 2 and 7 years [4]. The deletion, in this case, encompasses the GK gene; therefore, assessing glycerol levels in plasma and urine may be helpful. A low-fat diet is recommended because it can reduce glycerol production [5].

Additionally, we reviewed the clinical features of previously reported symptomatic female patients with Xp21 contiguous gene deletion (Table 1) [1,6-8]. Female carriers had mild-tomoderate intellectual deficiency. CK levels were elevated in four out of the ten patients reported, and CK levels were not reported for four patients. Heide et al. [1]reported that one patient presented with muscular pain during exercise, and two patients presented with global hypotonia, a neuromuscular symptom.

Table 1. Clinical features of female carriers with Xp21 deletion, overlapping with the present cases

\begin{tabular}{|c|c|c|c|c|c|c|c|c|}
\hline Reference & $\begin{array}{l}\text { Chromosome } \\
\text { region }\end{array}$ & $\begin{array}{l}\text { Deletion } \\
\text { size }\end{array}$ & Mb position [hg19] & $\begin{array}{l}\text { Age last } \\
\text { evalua- } \\
\text { tion }\end{array}$ & $\begin{array}{l}\text { Intellectual defi- } \\
\text { ciency }\end{array}$ & $\begin{array}{l}\text { Neuro- } \\
\text { muscular } \\
\text { symptoms }\end{array}$ & Epilepsy & $\begin{array}{c}\text { El- } \\
\text { evated } \\
\text { creatin } \\
\text { kinase }\end{array}$ \\
\hline \multicolumn{9}{|l|}{ Heide et al., 2015 [1] } \\
\hline Patient 1 & Xp21.3-p21.1 & $6.1 \mathrm{Mb}$ & 25,878,399-31,987,991 & $9 \mathrm{yr}$ & + (moderate) & - & - & - \\
\hline \multicolumn{9}{|l|}{ Fries et al., 1993 [6] } \\
\hline Family 1 & Xp21 & NR & NR & Adult & + (mild) & - & - & - \\
\hline Family 1 & Xp21 & NR & NR & $4 \mathrm{yr}$ & $+($ mild $)$ & NR & NR & + \\
\hline Family 2 & Xp21 & NR & NR & Adult & $+($ mild $)$ & NR & NR & NR \\
\hline Family 2 & Xp21 & NR & NR & Adult & $+($ mild $)$ & NR & NR & NR \\
\hline Patient 1 & Xp21.2 & NR & NR & $7 \mathrm{yr}$ & $+(\mathrm{NR})$ & $\begin{array}{l}+ \text { (global } \\
\text { hypotonia) }\end{array}$ & - & + \\
\hline \multicolumn{9}{|c|}{ Falsaperla et al., 2003 [8] } \\
\hline Patient 1 & Xp23.1-p21.1 & NR & NR & $2 \mathrm{yr}$ & + (moderate) & $\begin{array}{l}+ \text { (global } \\
\text { hypotonia) }\end{array}$ & - & + \\
\hline
\end{tabular}

+, present; -, not present; NR, not reported. 
Most male patients with Xp21 deletion syndrome present with electrolyte imbalance, caused by adrenal insufficiency, as the first manifestation, and it is the most fatal symptom [9]. However, Xp21 deletion syndrome rarely manifests as electrolyte imbalance in female carriers. Only one of the female patients presented with electrolyte imbalance or glucocorticoid deficiency. The main symptoms of female carriers are intellectual disability and progressive myopathy.

Clinical manifestations of female patients are due to $X$ chromosome inactivation. Symptoms vary depending on the size of the deletion and degree of inactivation. A limitation of our study is that we did not analyze the X chromosome inactivation pattern in our patient, which can differ between tissues (i.e., brain, muscle, and peripheral blood) [1].

This case report suggests that Xp21 gene deletion syndrome should be considered in both male and female patients with elevated serum CK levels and mild mental retardation. This study was limited in that we did not perform a detailed cognitive function test since her intellectual disability was very mild and there was no problem in peer conversation. We will closely monitor development of her cognitive function in the outpatient clinic. The progress of female carriers of Xp21 gene deletion is not well known. There have been only 10 female carriers of the disease reported so far, and the longest follow-up period of these female carriers was 20 years. Long-term follow-up of our patient's neuromuscular symptoms, cardiac involvement, and intelligence will contribute to the diagnosis and treatment of this disease.

\section{Authors' Contributions}

Conception and design: HL, YML. Acquisition of data: HL, JK. Analysis and interpretation of data: $\mathrm{HL}$, YML. Drafting the article: $J K_{1}$ HL. Critical revision of the article: HL, JHN, YML. Final approval of the version to be published: all authors.

\section{References}

1. Heide S, Afenjar A, Edery P, Sanlaville D, Keren B, Rouen A, et al. Xp21 deletion in female patients with intellectual disability: two new cases and a review of the literature. Eur J Med Genet 2015;58:341-5.

2. Wilson $K_{1}$ Faelan $C$, Patterson-Kane JC, Rudmann DG, Moore SA Frank $D$, et al. Duchenne and Becker muscular dystrophies: a review of animal models, clinical end points, and biomarker quantification. Toxicol Pathol 2017;45:961-76.

3. Joo MA, Choi MS, Kim EY, Park SK. A case of Xp21 contiguous gene deletion syndrome. Med J Chosun Univ 2013;38:92-5.

4. Sevim U, Fatma D, Ihsan E, Gulay C, Nevin B. A neonate with contiguous deletion syndrome in XP21. J Pediatr Endocrinol Metab 2011;24:1095-8.

5. Jamroz E, Paprocka J, Popowska E, Pytel J, Ciara E, Adamowicz M. Xp21.2 contiguous gene syndrome due to deletion involving glycerol kinase and Duchenne muscular dystrophy loci. Neurol India 2010:58:670-1.

6. Fries MH, Lebo RV, Schonberg SA, Golabi M, Seltzer WK, Gitelman SE, et al. Mental retardation locus in Xp21 chromosome microdeletion. Am J Med Genet 1993;46:363-8.

7. Shaikh MG, Boyes L, Kingston H, Collins R, Besley GT, Padmakumar B, et al. Skewed $X$ inactivation is associated with phenotype in a female with adrenal hypoplasia congenita. J Med Genet 2008;45:e1.

8. Falsaperla $R$, Romeo $G$, Sorge $A$, Bianchini $R$, DiGiorgio $A$, Trigilia $T$, et al. Mental retardation and early onset of weakness in a girl with a dystrophinopathy and a large Xp21-23 deletion. J Child Neurol 2003;18:79-81.

9. Wikiera $B$, Jakubiak A, Zimowski J, Noczyńska A, Smigiel R. Complex glycerol kinase deficiency - X-linked contiguous gene syndrome involving congenital adrenal hypoplasia, glycerol kinase deficiency, muscular Duchenne dystrophy and intellectual disability (IL1RAPL gene deletion). Pediatr Endocrinol Diabetes Metab 2012;18:153-7. 